\title{
Application of disease burden to quantitative assessment of health hazards for a decentralized water reuse system
}

Tingting Gao ${ }^{\mathrm{a}}$, Rong Chen ${ }^{\mathrm{a}, \mathrm{b}}$, Xiaochang Wang, ${ }^{\mathrm{a}}$, Huu Hao $\mathrm{Ngo}^{\mathrm{c}}, \mathrm{Yu}-\mathrm{You} \mathrm{Li}^{\mathrm{b}}$, Jinhong Zhou $^{\mathrm{a}}$, Lu Zhang ${ }^{\mathrm{a}}$

\footnotetext{
${ }^{a}$ Key Lab of Northwest Water Resource, Environment and Ecology, MOE, Xi'an University of Architecture and Technology, No.13 Yanta Road, Xi'an 710055, China

${ }^{\mathrm{b}}$ Department of Civil and Environmental Engineering, Graduate School of Engineering, Tohoku University, 6-6-06 Aza-Aoba, Aramaki, Aoba-ku, Sendai, Miyagi 980-8579, Japan

${ }^{\mathrm{c}}$ School of Civil and Environmental Engineering, Faculty of Engineering and Information Technology, University of Technology Sydney, Broadway, NSW 2007, Australia
}

\begin{abstract}
The aim of this article is to introduce the methodology of disease burden (DB) to quantify the health impact of microbial regrowth during wastewater reuse, using the case study of a decentralized water reuse system in Xi'an Si-yuan University, located in Xi'an, China. Based on field investigation findings, Escherichia coli (E. coli), Salmonella and rotaviruswere selected as typical regrowth pathogens causing potential health hazards during the reuse of reclaimed water. Subsequently, major exposure routes including sprinkler irrigation, landscape fountains and toilet flushing were identified. Mathematical models were established to build the relationship between exposure dose and disease burden by calculating the disability adjusted life year (DALY). Results of disease burden for this case study show that DALYs attributed to $E$. coli were significantly greater than those caused by other pathogens, and DALYs associated with sprinkler irrigation were higher than those originating from other routes. A correlation between exposure dose and disease was obtained by introducing a modified calculation of morbidity, which can extend the assessment endpoint of health risk to disease burden from the conventional infection rate.
\end{abstract}

\section{Abbreviations}

DB, disease burden; DALY, disability adjusted life year; WWTP, wastewater treatment plant; IID, intestinal infectious disease; DCPC, disease control and prevention centre; ID, infectious diarrhoea; PEG, polyethylene glycol; YLD, years of life lost due to disability; YLL, years of life lost due to premature death; CFR, case fatality rate; SDWT, Shanghai disability weight table; pppy, per person per year

\section{Keywords}

Disease burden; DALY; Health impact; Morbidity; Pathogen; Water reuse 


\section{Introduction}

The increase in pollution in existing water sources combined with a rising human population continues to increase the demand for alternative water sources. In this case, urban wastewater reclamation and reuse can not only effectively alleviate the current situation of water shortage, but can also directly reduce the amount of wastewater discharge (Hamilton et al., 2007). As a new non-potable water source, reclaimed water has been widely used for many purposes, including landscape replenishment, sprinkler irrigation and toilet flushing. However, although pathogenic microorganisms can be effectively removed by water treatment process, especially after chemical disinfection, such as chlorination adopted in this study, microbial regrowth of bacteria or viral pathogens such as Escherichia coli, Salmonella and rotavirus, due to the decreasing doses of disinfectant residuals during water reuse processes, or the enrichment of nutritional supplement such as biodegradable dissolved organic carbon (BDOC), nitrogen and phosphorus which supporting the regrowth of pathogens in reclaimed water, may bring about potential health risks, and thus may restrict the utilization of reclaimed water to a large extent (Hamilton et al., 2007 and Dan et al., 2013).

In Xi'an Si-yuan University, a decentralized water treatment, reclamation and reuse system was implemented to alleviate the pressure on water supply in this campus, and also to reduce the amount of wastewater discharge. For the safety reuse of wastewater, the sewage collected from the whole campus was carefully treated in the Si-yuan wastewater treatment plant (WWTP) through an A2O (Anaerobic/Anoxic/Oxic) unit and a membrane bioreactor. As a result, a 2-log reduction of pathogen removal could be achieved at least. Additionally, chlorination was implemented as the final step so as to achieve completely inactivation of all bacterial and viral pathogens. After being treated in the WWTP, reclaimed water was stored in the Si-yuan Lake and then be reused for a variety of purposes, such as landscape replenishing, sprinkling irrigation, toilet flushing etc. Since all pathogens have been inactivated by chlorination before being discharged to the Si-yuan Lake, potential microbial risks regarding to water reuse could be avoided to the maximum extent. However, microbial regrowth was detected by an investigation of 2-4-log increase of pathogen concentrations in the Si-yuan Lake, therefore, microbial risks and corresponding health hazards caused by specific pathogens regarding to water reuse by this decentralized water recycling system should be evaluated, and measures for the controlling of microbial regrowth should be made, such as the upgrading of treatment processes so as to decrease the concentrations of biodegradable organic matters (BOM), nitrogen, phosphorus and some other nutrients which are benefit for the regrowth of microbial (Brissaud, 2001). On this basis, the aim of this study is to: firstly, provide a quantitative assessment of potential health impacts caused by

pathogenic microorganisms during water reuse in Xi'an Si-yuan University; and secondly, offer recommendations for risk and/or disease control. 
Traditionally, infection rate has been commonly employed as an indicator of microbial risk caused by water reuse. This indicator's calculations are based on dose-response relationships, such as the exponential or beta-Poisson models (Haas et al., 1999). However, the application of these two models cannot distinguish between exposure populations with different characteristics, such as immunity status, age or gender. Besides, the infection rate obtained from dose-response analysis is defined as a probability of health risk, which can only represent the magnitude of probability that a certain health impact occurs. However, it cannot be used to describe the severity or duration of this specific health damage, and nor can it serve to provide a quantitative description of health loss after infection occurs (Geelen et al., 2009). In the development of certain health hazards, infection should be recognized as a middle step, occurring between exposure and clinically defined health damage, but not the endpoint of health outcomes resulting from microbial pollution. Although the probability of infection may be high for an individual exposed to pathogenic microorganisms, the ultimate health damage may not be severe, because such a scenario's development generally depends on a series of complicated mechanisms. Therefore, the ultimate health impact caused by microbiological contaminants should not only be judged by infection rates, but evaluated with extended indices.

Disability adjusted life year is an indicator originally designed for the evaluation of overall disease burden due to global or regional disease outbreaks. It is expressed as a sum of healthy years lost due to disability and premature death (Murray and Lopez, 1996). DALY is recognized and adopted as a valid indicator for the evaluation of disease burden caused by environmental pollution (Beyer, 2016), and extends the evaluation of health impact from infection risk assessment. This is because it can comprehensively assess the magnitude of health damage after pollution outbreaks (Gao et al., 2015). In this study, the health hazards caused by the selected waterborne pathogens associated with water reuse in Xi'an Si-yuan University were evaluated by disease burden. In accordance with the methodology of disease burden expressed as DALY, assessing the health impact was conducted using the following steps: the characterization of exposure routes and exposure doses; the estimation of morbidity based on a modified dose-response relationship; and the evaluation of disease burden using DALY. As a consequence, major risk factors leading to the greatest disease burden were confirmed, and instructive measures for future risk or disease control were developed.

\section{Methods}

\subsection{Case description}

Xi'an Si-yuan University is located in the south-eastern suburbs of Xi'an in China, an area which is undergoing development and construction. Urban water supply and sewage collection systems are not available in this campus, and in fact the only available sources of 
water are five groundwater wells with a combined maximum capacity of $3000 \mathrm{~m}^{3} / \mathrm{d}$. However, the actual water demand for this campus is roughly estimated as $6000 \mathrm{~m}^{3} / \mathrm{d}$, more than half of which is for non-potable water. This consumption demand was far beyond the water supply capability and finally led to water supply intension. Therefore, a decentralized sewage collection system has been implemented based on the construction and operation of Si-yuan wastewater treatment plant so as to alleviate the pressure on water supply and to reduce the amount of sewage discharge as well. As illustrated in Fig. 1, groundwater is pumped for both potable and non-potable uses through drinking water pipelines, wastewaters generated from the whole campus, including black water, grey water, and kitchen wastewater collected from university canteens are gathered by an independent sewage collection system and sent to the WWTP for onsite treatment, reclamation and reuse. With a treatment capacity of $2500 \mathrm{~m}^{3} / \mathrm{d}$, the gathered wastewater is treated through a series of facilities, including a regulation basin to receive the collected wastewater, fine screens to remove coarse solid particles, and a biological treatment unit in anaerobic/anoxic/oxic $\left(\mathrm{A}^{2} \mathrm{O}\right)$ array followed by a membrane bioreactor (MBR) where submerged hollow fibre membrane modules are employed for organic degradation. Additionally, a disinfection tank is designed for further inactivation of pathogenic microorganisms before water reuses. Reclaimed water reused for sprinkler irrigation and landscape replenishing is not recyclable, but for toilet flushing it could be collected and re-treated in the WWTP for the next recycling process. In this campus, water reuse has accounted for $53 \%$ of the total water consumption, and thus become an indispensable source of water supply.

For non-potable reuse purposes, reclaimed water should be produced with a limitation or control of the amount of pathogenic microorganisms before being directly contacted with the exposed individuals. In order to ensure the quality of treated wastewater and to decrease the health hazard due to pathogenic contamination as well, disinfection is an indispensable step before water reclamation and reuse, since the majority of pathogens could be inactivated during this stage before being discharged into the environment (Asano, 1998 and Bixio et al., 2006). As shown in Fig. 2, a 2-log reduction of pathogens could be achieved at least by a combination of $\mathrm{A}^{2} / \mathrm{O}$ and MBR in the biological treatment unit in Si-yuan WWTP. However, the hazard of microbial intrusion still exists since a complete inactivation has not been achieved by this stage. After being treated in the disinfection tank with an addition of sodium hypochlorite $(10 \%) 70 \mathrm{~L} / \mathrm{d}$, an average of $1-\log$ reduction of pathogens was further achieved and all residual pathogens was finally inactivated. Therefore, disinfection is the last barrier to prevent microbial intrusion to the water environment, and also to provide a guarantee to reduce health hazard before water reclamation and reuse (Lazarova et al., 2001 and Verlicchi et al., 2011). In this study, disinfection is not only indispensable for water treatment but also 
for the operation of an independent water recycling system, such as the Si-yuan water reuse system.

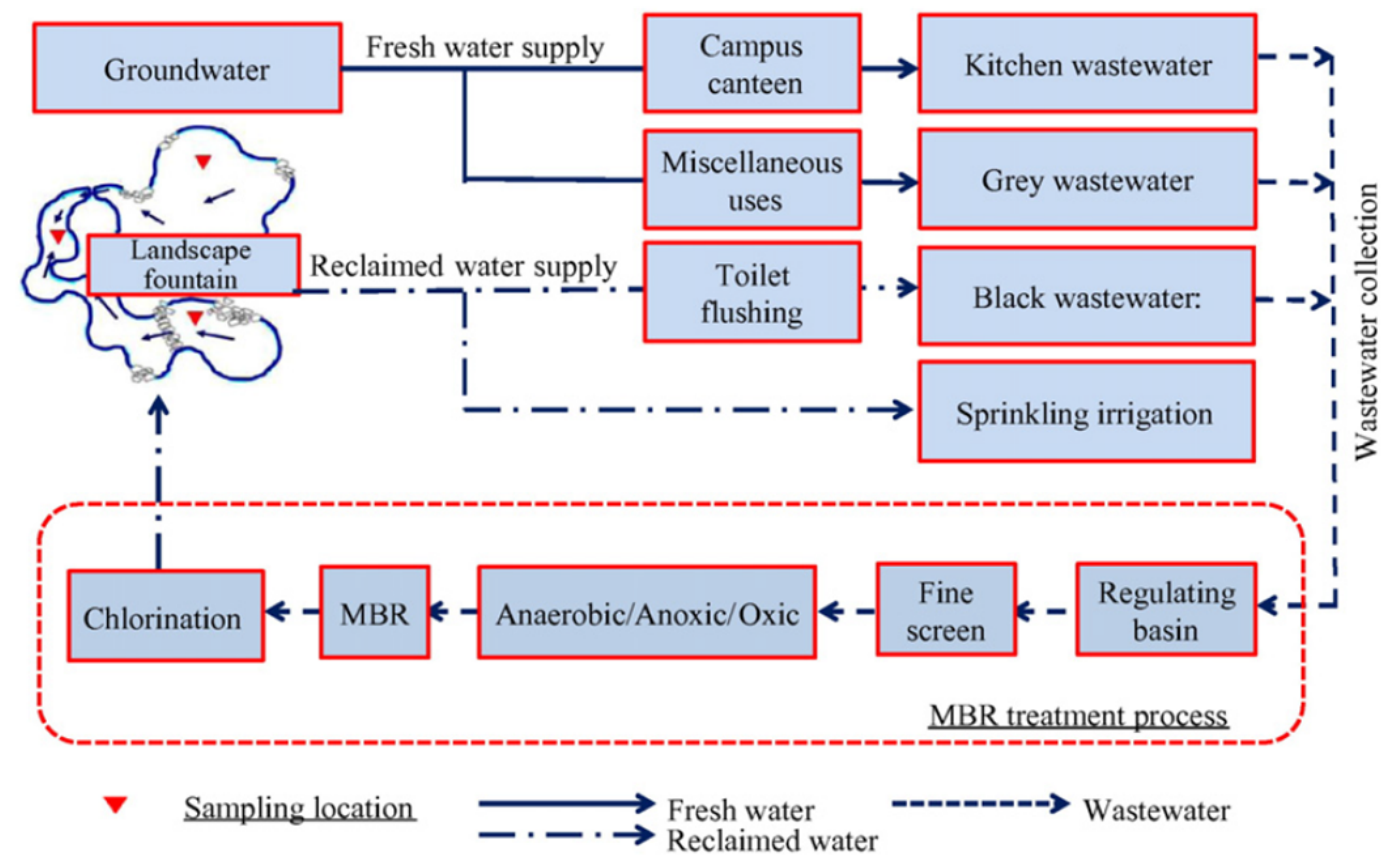

Fig. 1. The wastewater treatment, reclamation and reuse system in Xi'an Si-yuan University.

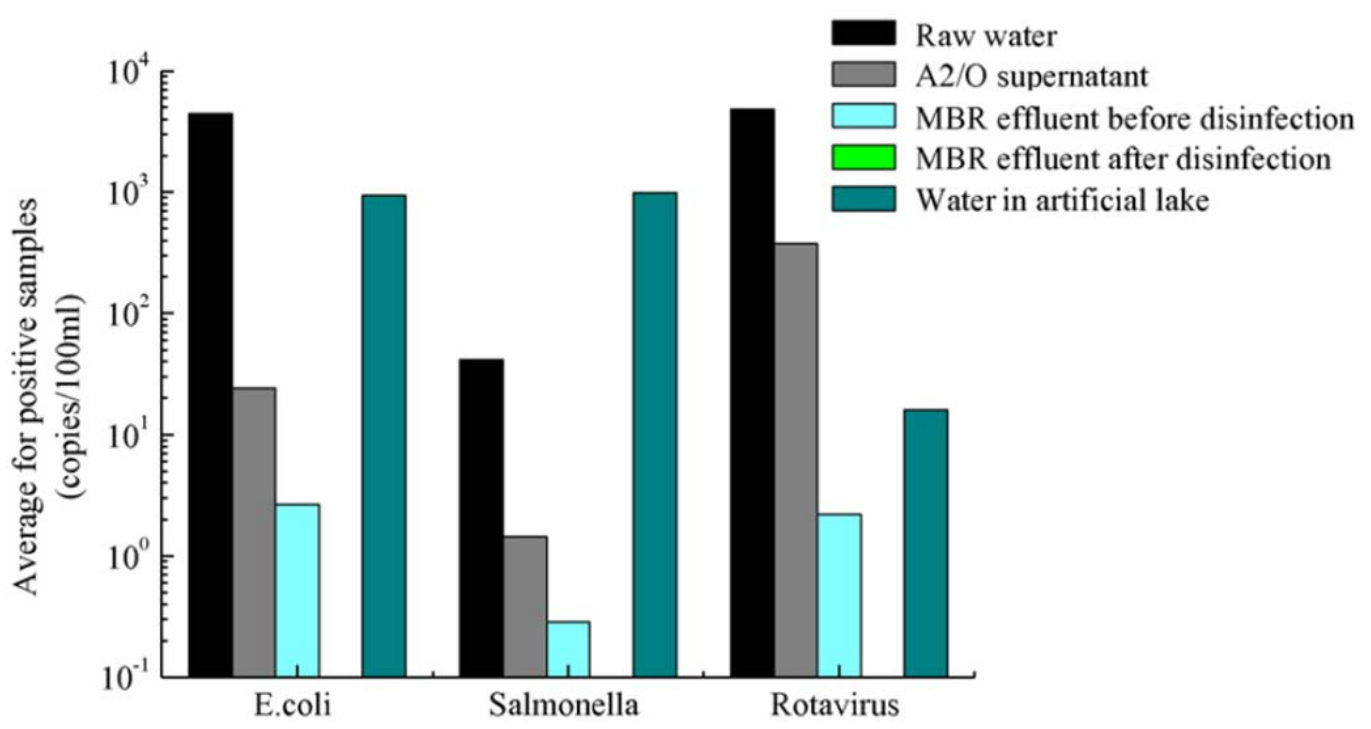

Fig. 2. Average concentrations of selected pathogens detected in different stages of wastewater treatment and the artificial lake replenished with reclaimed water.

\subsection{Exposure characterization}

Exposure to an environmental contaminant is a prerequisite for causing health damage and leading to disease burden. The process of exposure characterization includes the selection of 
significant risk factors for the development of waterborne diseases, the detection of selected pathogens based on experimental analysis, and the determination of major exposure routes as well as exposure doses. These are regarded as essential steps before quantifying the dosemorbidity relationship, which would be adopted as an input to the DALY calculation. The three parts involved in exposure characterization are presented in detail in the following subsections.

\subsection{Selection of waterborne pathogens}

Statistical results from a local epidemiological survey revealed that intestinal infectious disease (IID) caused by pathogenic microorganisms has a very high incidence in Xi'an city. From 1999 to 2000 , the incidence of IID was estimated to be $2.60 \times 10^{-3}$, accounting for $89.73 \%$ of the total incidence of all kinds of infectious diseases accumulated during the previous 10 years in Xi'an (Cui, 2005). In addition, surveillance data from the Xi'an Disease Control and Prevention Center (DCPC) indicated that more than 50\% of cases were determined to be infectious diarrhoea (ID), which can potentially lead to extensive damage of the human intestinal system. The other $50 \%$ of cases were reported as bacterial dysentery caused by Shigella, cholera caused by Vibrio cholerae, amoebic dysentery caused by Amoeba, viral hepatitis caused by Hepatitis virus, poliomyelitis caused by Poliovirus, etc. However, since the outbreak of these diseases are not common regarding to water reuse in Xi'an as investigated by Xi'an Disease Control and Prevention Center, the selection of waterborne pathogens in this study mainly focus on the contribution to cause infectious diarrhoea. The finding that the majority of ID occurring among the urban population was caused by Escherichia coli $(E$. coli), Salmonella and rotavirus was also based on epidemiological investigation. E. coli is a traditional hygiene index that represents the extent of water pollution by faeces. Several strains, such as enterohaemorrhagic E. coli, enterotoxigenic E. coli and enteropathogenic E. coli can lead to acute intestinal disease after ingestion (Bitton, 2005). Salmonella is a common intestinal pathogen that exists in wastewater. Waterborne diseases resulting from Salmonella, such as typhoid, have prevailed and break out in many regions of China. They are especially severe in Guizhou province (Tao et al., 2003). Rotavirus is a leading cause of childhood diarrhoea, and almost 50\% of infected children may develop severe diarrhoea. Adult diarrhoea caused by rotavirus can also lead to the outbreak of viral gastroenteritis (Gerba et al., 1985). For these reasons, E. coli, Salmonella and rotavirus were selected as major risk factors for water reuse causing intestinal diseases in Xi'an Si-yuan University.

\subsection{Detection of selected pathogens}

In order to illustrate the survive/fade of pathogens in the processes of wastewater treatment before water reuse for Si-yuan University, concentrations and log-removal rates were 
estimated for different stages of treatment adopted in Si-yuan WWTP. The preliminary treatment of wastewater by fine screens could bring about $0.2-0.4-\log$ removal for almost all pathogens. And the biological treatment units, namely the $\mathrm{A}^{2} \mathrm{O}$ tank, could achieve almost identical removal rate (1.3-1.7-log) for both bacteria and viruses. The successive treatment stage-MBR after $\mathrm{A}^{2} \mathrm{O}$ showed a varied removal for $E$. coli (2.6-log) and other pathogens $(0.7-1.0-\log )$. Additionally, chlorination implemented after bio-treatment was proved to be effective for eliminating all pathogens since all residual pathogens were non-detectable in the treated effluent. However, although pathogenic microorganisms could be effectively and completely removed by wastewater treatment processes, especially the disinfection stage adopted in Si-yuan WWTP, a frequently detection of pathogens in the artificial lake of Siyuan University indicates the result of microbial regrowth during the storage of reclaimed water in an open reservoir. According to recently studies, three explanations could be used to account for the phenomenon of microbial regrowth in reclaimed water: (1) after general disinfection, several pathogens, especially bacteria, could stay in a viable but non-cultivable state, and being in this state, the concentrations of pathogens could not be detected, however the toxicity and pathogenicity are still reserved, thus these pathogens could grow again after the pressure of disinfection relieved in the reclaimed water (Oliver, 2005); (2) after the amount of disinfectant residuals gradually decreased to a certain degree in the reclaimed water, a self-repair of the damaged DNA for several pathogens could be achieved by two mechanisms, namely "photo-reactivation" and "dark repair", thus pathogen regrowth may occur (Lin et al., 2016); (3) biodegradable organic matters (BDOM) and other nutrients such as nitrogen and phosphorus existed in the reclaimed water are regarded as essential nutritional supplements facilitating the occurrence of microbial regrowth, thus under appropriate conditions, such as proper temperatures, sunlight and $\mathrm{pH}$, microbial regrowth may occur (Van Nevel et al., 2013). On this basis, the regrowth of pathogenic microorganisms may consequently pose directly threat to environmental health and public safety as well, therefore continuously tracking of microbial hazards during the whole processes of water reclamation and reuse is indispensable.

The concentrations of selected pathogens were detected by a real-time PCR technique. Before experimental analysis, 33 samples of $2 \mathrm{~L}$ of water were collected from the artificial lake in Si-yuan University. Each sample was collected as a mixture of equal proportions obtained from three locations evenly distributed in this lake, as labelled in Fig. 1. For the detection of $E$. coli, water samples were first filtered through a series of mixed cellulose ester membranes with pore sizes of $0.65 \mu \mathrm{m}, 0.45 \mu \mathrm{m}$ and $0.22 \mu \mathrm{m}$ after $\mathrm{pH}$ adjustment. The filtrate was magnetically stirred at $350 \mathrm{rpm}$ for $3 \mathrm{~min}$ before elution, and the eluate was centrifuged at $14,000 \mathrm{rpm}$ for $30 \mathrm{~min}$ at $4{ }^{\circ} \mathrm{C}$. From the concentrates, DNA was extracted using a Genomic DNA Extraction kit (Bio Tech, China) following the manufacturer's instruction. In this study, the detected $E$. coli was all regarded as pathogenic so as to obtain a 
probable maximum health risk. Although the identification of $E$. coli is conservative and may lead to over-estimating the health impact, the outcome may be relatively safe for disease control and risk management. For the detection of Salmonella and rotavirus, water samples were firstly filtered through a series of mixed cellulose ester membranes with pore sizes of $0.65 \mu \mathrm{m}, 0.45 \mu \mathrm{m}$ and $0.22 \mu \mathrm{m}$ after the adjustment of $\mathrm{Mg}^{2+}$ concentration. The filtrates were then washed with acid and recovered by lye. Samples were neutralized before the adjustment of polyethylene glycol (PEG)-6000 and $\mathrm{NaCl}$ concentrations; and afterwards the concentrates were stirred overnight at $100 \mathrm{rpm}$ at $4{ }^{\circ} \mathrm{C}$ and then centrifuged at $9000 \mathrm{rpm}$ for $30 \mathrm{~min}$ at $4{ }^{\circ} \mathrm{C}$. The supernatant was discarded and the deposit was re-suspended in $1 \mathrm{~mL}$ ultrapure water. $140 \mu \mathrm{L}$ of the concentrate was used to extract the viral genomic RNA using a QIAamp Viral RNA kit (Qiagen, Valencia, CA, US) following the manufacturer's instruction. The extracted RNA was stored at $-80{ }^{\circ} \mathrm{C}$ before use. Reverse transcription (RT) was carried out using a PrimeScript ${ }^{\circledR}$ RT reagent Kit with gDNA Eraser (Takara, Otsu, Japan) following the protocol described by the manufacturer. The extracted viral RNA $(5 \mu \mathrm{L})$ was mixed with a mixture containing $2 \mu \mathrm{L} 5 \times$ gDNA Eraser Buffer, $1 \mu \mathrm{L}$ gDNA Eraser and $2 \mu \mathrm{L}$ RNase Free $\mathrm{dH} 2 \mathrm{O}$ and then incubated at $42^{\circ} \mathrm{C}$ for $2 \mathrm{~min}$. The treated mixture was reacted with a reaction mixture containing $4 \mu \mathrm{L} 5 \times$ PrimeScript ${ }^{\circledR}$ Buffer, $1 \mu \mathrm{L}$ PrimeScript ${ }^{\circledR}$ RT Enzyme Mix, $1 \mu \mathrm{L}$ RT Primer Mix and $4 \mu \mathrm{L}$ RNase Free $\mathrm{dH} 2 \mathrm{O}$ at $37^{\circ} \mathrm{C}$ for $15 \mathrm{~min}$ and $85^{\circ} \mathrm{C}$ for $5 \mathrm{~s}$. The RT sample prepared was then stored at $-20^{\circ} \mathrm{C}$ before analysis.

Real-time quantitative PCR was conducted for the quantification of $E$. coli, Salmonellaand rotavirus using SYBR ${ }^{\circledR}$ Primix Dimer Eraser ${ }^{\mathrm{TM}}$ kit (Takara, Japan) in an iCycler iQ5 Real Time PCR Detection System (Bio-Rad, Hercules, California, USA). The primers/probes used are summarized in Table 1. The amplification of genomic DNA was carried out in a reaction medium containing $12.5 \mu \mathrm{L}$ of SYBR Premix DimerEraser ${ }^{\mathrm{TM}}$, $400 \mathrm{nmol} / \mathrm{L}$ of each primer and sterilized distilled water to a total volume of $25 \mu \mathrm{L}$. The reaction condition for $E$. coli was as below: initial denaturation at $95^{\circ} \mathrm{C}$ for $30 \mathrm{~s}$, followed by 40 cycles of denaturation at $95^{\circ} \mathrm{C}$ for $15 \mathrm{~s}$, annealing at $65^{\circ} \mathrm{C}$ for $30 \mathrm{~s}, 72{ }^{\circ} \mathrm{C}$ for $60 \mathrm{~s}$ and $79^{\circ} \mathrm{C}$ fluorescent signal acquirement. The procedures for Salmonella and rotaviruswere similar to the above except for the different temperatures of annealing and fluorescent signal acquirement as shown in Table 1. The quantification of rotavirus was performed using Primix the Ex Taq ${ }^{\mathrm{TM}}$ kit (Takara, Otsu, Japan) in 7500 Real Time PCR system (Applied Biosystems, USA) under the following conditions: $20 \mu \mathrm{L}$ reaction volume containing $10 \mu \mathrm{L}$ of Primix the Ex Taq ${ }^{\mathrm{TM}}, 0.4 \mu \mathrm{L}$ of ROX Reference Dye II, $200 \mathrm{nmol} / \mathrm{L}$ of each primer, $400 \mathrm{nM}$ of TaqMan probe, initial denaturation at $95{ }^{\circ} \mathrm{C}$ for $2 \mathrm{~min}$, followed by 45 cycles of denaturation at $95^{\circ} \mathrm{C}$ for $15 \mathrm{~s}$ and $60{ }^{\circ} \mathrm{C}$ for $60 \mathrm{~s}$. 
Table 1. Primers and probes used for real-time PCR analysis.

\begin{tabular}{|c|c|c|c|c|}
\hline $\begin{array}{l}\text { Primers/ } \\
\text { probes }\end{array}$ & Sequences $\left(5^{\prime}-3^{\prime}\right)$ & $\begin{array}{l}\text { Size } \\
(b p)^{a}\end{array}$ & PCR programmes & Reference \\
\hline \multicolumn{5}{|l|}{ E. coli } \\
\hline EC-F & TGAGCGGCTGGCATGAGTCATAC & 241 & Annealing at $65^{\circ} \mathrm{C}$ & $\begin{array}{l}\text { Ahmed et al. } \\
\text { (2007) }\end{array}$ \\
\hline EC-R & TCGATCCCCATCGTCACCAGAGG & & $\begin{array}{l}\text { Signal acquiring at } \\
79^{\circ} \mathrm{C}\end{array}$ & \\
\hline \multicolumn{5}{|c|}{ Salmonella } \\
\hline 139 & GTGAAATTATCGCCACGTTCGGGCAA & 284 & Annealing at $65^{\circ} \mathrm{C}$ & $\begin{array}{l}\text { Rahn et al. } \\
(1992)\end{array}$ \\
\hline 141 & TCATCGCACCGTCAAAGGAACC & & $\begin{array}{l}\text { Signal acquiring at } \\
84^{\circ} \mathrm{C}\end{array}$ & \\
\hline \multicolumn{5}{|c|}{ Rotavirus } \\
\hline NSP3-F & ACCATCTACACATGACCCTC & 89 & & $\begin{array}{l}\text { Pang et al. } \\
(2004)\end{array}$ \\
\hline NSP3-R & GGTCACATAACGCCCC & & $15 \mathrm{~s}$ at $95^{\circ} \mathrm{C}$ & \\
\hline \multirow[t]{2}{*}{ Probe } & $\begin{array}{l}\text { 6FAM- } \\
\text { ATGAGCACAATAGTTAAAAGCT }\end{array}$ & & $60 \mathrm{~s}$ at $60^{\circ} \mathrm{C}$ & \\
\hline & AACACTGTCAA-BHQ1 & & & \\
\hline
\end{tabular}

${ }^{\mathrm{a}}$ Amplicon size of real-time PCR products.

\subsection{Determination of exposure route and exposure dose}

In accordance with field investigation findings, inhalation with reclaimed water through sprinkler irrigation, landscape fountains and toilet flushing were identified as typical exposure routes in this study. For examples, the spray of reclaimed water from sprinkler irrigation can be inhaled by college gardeners and nearby pedestrians. Water from landscape fountains can be inhaled by pedestrians who occasionally walk by Si-yuan Lake. Reclaimed water used in toilet flushing can be inhaled by the general public.

For the exposure pathways discussed above, the single exposure dose $(N)$ of particular pathogens can be calculated by Eq. (1) (Chen et al., 2006):

$$
\mathrm{N}=\mathrm{C} \times \mathrm{V} \quad \text { equation (1) }
$$

where $N$ is the exposure dose of a particular pathogen from a particular pathway, copies/d; $C$ is the exposure concentration of the pathogen detected in water, copies/L; and $V$ is the inhalation volume per day regarding each exposure route, $\mathrm{L} / \mathrm{d}$. 
For sprinkler irrigation and landscape fountains, the daily inhalation volume of reclaimed water $(V)$ can be calculated by Eq. (2) (He et al., 2006):

$$
\mathrm{V} \text { inhalation }=\mathrm{IR} \times \mathrm{ET} \text { inhalation } \times \mathrm{F} \times 0.63 \quad \text { Equation }(2)
$$

where $V_{\text {inhalation }}$ is the inhalation volume per day through inhalation, $\mathrm{L} / \mathrm{d}$; $I R$ is the respiration rate, $\mathrm{m}^{3} / \mathrm{h} ; E T_{\text {inhalation }}$ is the exposure duration, $\mathrm{h} / \mathrm{d} ; F$ is the concentration of water sprayed into the air, $\mathrm{L} / \mathrm{m}^{3}$; and 0.63 is the absorption rate (USEPA, 1997). The determination of exposure parameters such as $E T_{\text {inhalation }}$ involved in Eq. (2) was based on field investigations. Other parameters for sprinkler irrigation and landscape fountains were determined from the literature. For example, $I R$ was suggested by Xie et al. (2009) while $F$ was advocated by He et al. (2006), as summarized in Table 2.

Table 2. Exposure parameter for sprinkler irrigation and landscape fountains.

$\begin{array}{llll}\text { Exposed population } & I R\left(\mathrm{~m}^{3} / \mathrm{h}\right) & F\left(\mathrm{~L} / \mathrm{m}^{3}\right) & \text { ETinhalation }(\mathrm{h} / \mathrm{d})\end{array}$

\section{Sprinkler irrigation}

$\begin{array}{llll}\text { Gardener } & 1.6 & 0.033 \text { (on-site) } & 4.0 \\ \text { Pedestrian } & 1.6 & 0.0167 \text { (off-site) } & 2.5\end{array}$

\section{Landscape fountains}

Pedestrian $\quad 1.6 \quad 0.0167 \quad 1.0$

Because of limited available data, exposure parameters for toilet flushing were determined by referring to a previous analysis (Dorevitch et al., 2011), which recommended the inhalation volume of reclaimed water per day $(V)$ should be $0.05 \mathrm{~mL} / \mathrm{d}$.

\subsection{Dose-morbidity analysis}

\subsubsection{Basic consideration}

Because of the aforementioned shortcomings of infection risk assessment by dose-response analysis, health impact in this study was evaluated in terms of disease burden using the DALY. To evaluate the disease burden caused by microbiological contaminants, or conversely, to apply a reference threshold of tolerable disease burden, the health outcomes following each specific exposure need to be defined, and models of disease process must be designed, as shown in Fig. 3. In this figure, either asymptomatic or symptomatic disease may occur following the ingestion of a certain amount of pollutant. In symptomatic cases, human cells, tissues or organs appear damaged after exposure, followed by various degrees of illness symptoms or even death. Before the quantification of disease burden due to microbial pollution, transition probabilities including morbidity and mortality between exposure and 
certain health outcomes should be established and estimated for the subsequent DALY calculation. However, data on fatalities were not collected and therefore cannot be considered in this research. Only symptoms of various intestinal diseases, such as watery or bloody diarrhoea were documented, and morbidities for these outcomes were estimated by using a modified dose-response relationship explained below. Furthermore, the process of dosemorbidity analysis conducted in this study does not only enable the partitioning of an exposed population over different stages of disease development, it also provides a prerequisite for disease burden calculations covering all relevant health outcomes.

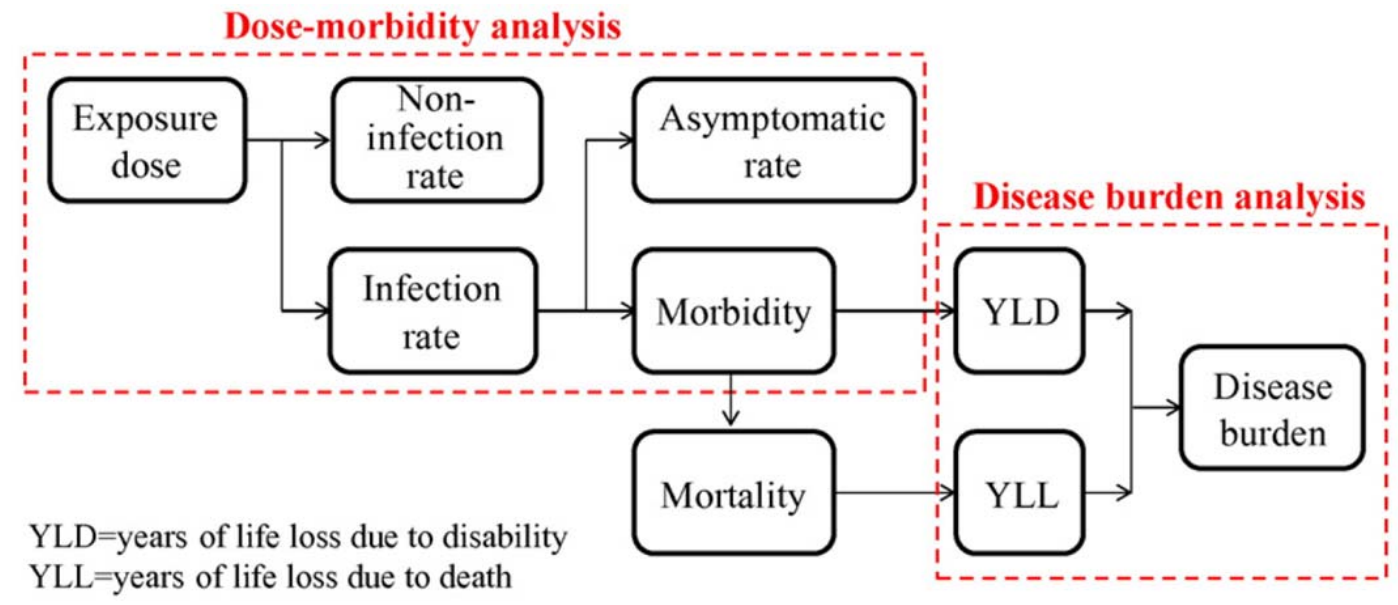

Fig. 3. Process of disease development from exposure to disease burden.

Since illness is conditional on infection, the probability of becoming ill $\left(P_{\text {ill }}\right)$ can be calculated by multiplying the infection rate $\left(P_{\text {inf }}\right)$ with the probability of illness given infection $\left(P_{i l l i \text { inf }}\right)$, shown as Eq. (3). Therefore, the estimation of $P_{\text {inf }}$ and $P_{\text {illlinf }}$ are inevitable steps in establishing the dose-morbidity relationship:

$P_{\text {ill }}=P_{\text {inf }} \times P_{\text {ill } / \text { inf }}$.

\subsubsection{Infection rate (Pinf)}

According to microbial risk assessment by the current dose-response method, the infection rate (Pinf) due to a single exposure has been studied adequately by a single-hit model as shown in Eq. (4) (Haas et al., 1999). For this model, in the case of ' $m$ ' successive defensive barriers in a human body, the probability that any single pathogen successfully passes all barriers and finally survives to reach a proper position to cause infection is defined as $P m$. The $P m$ is always assumed to be a constant value:

$P_{\text {inf } / d}(D)=1-e^{-P_{m} D}$.

However, the susceptibility of a human host to infection generally depends on a number of recognized and unrecognized factors, and the characterization of these factors was not taken 
into consideration in Eq. (4). Additionally, for the DALY calculation, characterization of the exposed population is necessary because the extent or duration of certain health damage caused by the same pathogen that was interpreted by DALY is generally distinguished between hosts. Although a beta distribution has been suggested by Haas et al. (1999) as representing the variation in $P m$ between hosts and a beta-Poisson model proposed to quantify the infection risk instead of using an exponential model, specific factors that may affect the response of different exposed populations were not identified and the ways these factors contribute were not interpreted clearly either. As a consequence, two welldocumented factors, namely immune status and age, which reflect the variation in Pm between different hosts, were considered and integrated to modify Eq. (4) in this study. For the description of immune status, 'human antibody level', which reflects the protection by the humoral immune system, is utilized. The higher the human antibody level, the greater will be the defensive ability. Referring to the description of age effect, an age-weight function ' $C x e^{-} \beta x$ ' is used as suggested by the World Health Organization (WHO) studies (Murray and Lopez, 1996). Normally, children ( $<2$ years old) and older people $(>60$ years old) are much more susceptible to infection by pathogens than are younger adults. For children, the mucosal immune system is relatively immature and inactive, while for older people, the immune system is gradually declining; consequently the resistance to external disturbance for these two age groups is comparatively weak. On this basis, a logit function was used in this study to model Pmwith immune status and age, shown as Eq. (5), and the modified single-hit model, indicated as Eq. (6), where $x$ represents human antibody level and $y$ represents average age. Other parameters such as $a, b, c$ and $\beta$ are defined as doseresponse coefficients:

$$
\begin{aligned}
& \operatorname{Logit}\left(P_{m}\right)=\log \left(\frac{P_{m}}{1-P_{m}}\right)=\mathrm{a}+\mathrm{bx}+\mathrm{cy} e^{-d y} \\
& P_{\text {inf } / d}(D, x, y)=1-e^{-D P_{m}(x, y ; a, b, c, \beta)} .
\end{aligned}
$$

Because of data limitations, $x$ for E. coli, Salmonella and rotavirus was recommended to be 0.79 (Teunis et al., 2002), and $y$ was determined to be 20 years old, based on field investigations in Si-yuan University. Other parameters such as ' $a$ ' and ' $b$ ' were suggested to be 3.56 and -53.2 , respectively, by Teunis et al. (2002), while ' $c$ ' and ' $\beta$ ' were recommended by the WHO studies (Murray and Lopez, 1996) to be -0.1685 and 0.04 , respectively. 


\subsubsection{Illness resulting from infection ( $\left.P_{\text {illinf }}\right)$}

In this paper, the only morbidity response we considered was for acute gastroenteritis. According to Teunis et al. (1999), the modelling of $P_{\text {illinf }}$ depends mainly on three components: an infected host, a hazard of illness and duration of infection. As illness is conditional upon infection, infection duration is the key variable in the dose-morbidity relationship, since a host with strong defences against pathogens is assumed to clear infection rapidly, while a pathogen of high virulence is assumed to sustain intra-intestinal growth for long periods. Accordingly, $P_{\text {illinf }}$ is modelled as Eq. (7), in which $\gamma$ and $\sigma$ represent the scale and shape parameters for gamma distribution of infection duration (Teunis et al., 1999). Parameters involved in Eq. (7) were determined by fitting with several human experimental datasets (Teunis et al., 1996). As a result, for $E$. coli, $\gamma$ and $\sigma$ were estimated to be $2.28 \times 10^{-2}$ and $2.46 \times 10^{-2}, \quad$ respectively; while for Salmonella, $\gamma$ and $\sigma$ were $1.00 \times 10^{-16}$ and $3.40 \times 10^{8}$, respectively; and for rotavirus, $\gamma$ and $\sigma$ were $1.73 \times 10^{-3}$ and $2.46 \times 10^{3}$, respectively.

$P_{\text {ill } / \text { inf }}=1-(1+\gamma \mathrm{D})^{-\sigma}$

The probability of becoming ill per day $\left(P_{\text {illld }}\right)$ is calculated by Eq. $(8)$ as a multiplication of infection rate $\left(P_{\text {inffl }}\right)$ obtained from the modified single-hit model Eq. $(6)$ and the probability of illness caused by infection $\left(P_{\text {illinf }}\right)$ calculated by Eq. (7). However, for the DALY calculation, evaluation of annual probability of illness $\left(P_{i l l / y}\right)$ is necessary, and is calculated by Eq. (9) in accordance with the determination of annual exposure frequency $(n)$ by field investigation. For sprinkler irrigation, $n$ was determined as $306 \mathrm{~d} / \mathrm{y}$ for gardener, and $244 \mathrm{~d} / \mathrm{y}$ for pedestrian. Meanwhile for landscape fountains, $\mathrm{n}$ was determined to be $244 \mathrm{~d} / \mathrm{y}$ for pedestrian, and for toilet flushing, $\mathrm{n}$ was determined as $365 \mathrm{~d} / \mathrm{y}$ for the general public.

$P_{i l l / d}(D, x, y)=P_{\text {inf } / d}(D, x, y) \times P_{\text {ill } / \text { inf }}(D)$

$P_{\text {ill } / y}(D, x, y)=1-\left(1-P_{\text {ill } / d}(D, x, y)\right)^{n}$

\subsection{Disease burden evaluation using the DALY}

\subsubsection{Concepts of the DALY method}

The DALY is an indicator suggested by the WHO for quantifying international and/or regional disease burden (Murray and Lopez, 1997). This indicator uses a metric to quantify healthy life lost under various disability conditions or due to premature death. The quantification of disease burden in terms of the DALY also takes into account the characterization of disease symptoms, disease severity and duration (Wei et al., 2012). Therefore, the DALY can be used for extended assessment of health impacts based on 
infection risk analysis (Gao et al., 2015). The results of the DALY calculation do not only provide overall quantifications of the reduction of life length, but also give accurate descriptions of the decrease in life quality as well (Havelaar and Melse, 2003). Eq. (10) is the fundamental expression for the DALY calculation, which is represented as a sum of healthy years of life lost due to disability $(Y L D)$ and healthy years of life lost by premature death (YLL). According to the basic concepts for constructing the DALY (Murray and Lopez, 1997), YLD is calculated as a product of Pilly, disability weight $(W)$ and disease duration $(T)$, shown as Eq. (11) (WHO, 2013), while YLL is calculated as a multiplication of Pilly, case fatality rate $(C F R)$ and average standard life expectancy $(L)$, shown as Eq.(12) (WHO, 2013):

$D A L Y=Y L D+Y L L$

$Y L D=P_{\text {ill } / y}(D, x, y) \times W \times T$

$Y L L=P_{\frac{i l l}{y}}(D, x, y) \times C F R \times L$.

\subsubsection{Determination of disease parameters}

Since the available data is very limited, disease parameters such as $W, T, C F R$ and $L$ involved in the DALY calculation were determined based on global or regional disease burden studies, as summarized in Table 3. As a result, $W$ for watery diarrhoea caused by $E$. coli was suggested by Murray and Lopez (1996), while $W$ for other disability outcomes was determined to refer to the Shanghai Disability Weight Table (SDWT) of China (Gu et al., 2002). SDWT was established based on a sampling survey for 84 common diseases among Shanghai residents. $T$ was determined according to a clinical survey on various intestinal infectious diseases reported by the China DCPC. For death outcome, $L$ was calculated as life expectancy minus average age of the exposed population. According to the census statistics in 2010, life expectancy in Xi'an was 74.68 years, while the average age of students in Xi'an Si-yuan University was taken to be 20 years old. Thus, $L$ was calculated as 54.68 years.

Table 3. Disease parameter and associated values for DALY calculation.

\begin{tabular}{llll}
\hline Pathogen & $\begin{array}{l}\text { Disability } \\
\text { weight }\end{array}$ & $\begin{array}{l}\text { Disease duration } \\
\text { (days) }\end{array}$ & $\begin{array}{l}\text { Likelihood of health } \\
\text { outcomes }\end{array}$ \\
\hline $\begin{array}{llll}\text { E. coli } \\
\text { Watery diarrhoea }\end{array}$ & 0.067 & 2.5 & $5.30 \times 10^{-1}$ \\
$\quad$ Bloody diarrhoea & 0.44 & 6 & $4.70 \times 10^{-1}$ \\
$\quad \begin{array}{l}\text { Death } \\
\text { Salmonella }\end{array}$ & 1 & & $2.70 \times 10^{-4}$ \\
$\quad$ Typhoid & 0.60 & 24.5 & 1.00 \\
\hline
\end{tabular}




Death 1100

\section{Rotavirus}

$\begin{array}{llll}\text { Acute gastroenteritis } & 0.60 & 4 & 1.00 \\ \text { Death } & 1 & & 7.00 \times 10^{-3}\end{array}$

\section{Results and discussion}

\subsection{Exposure dose calculation}

The average concentrations of pathogens detected by real time-PCR (copies/100 mL) at different stages of wastewater treatment processes are shown in Fig. 2. As show in this figure, all bacterial and viral pathogens were inactivated after the MBR effluent being disinfected by chlorine. However, an occurrence of 2-4-log increase of pathogen concentrations was detected after the reclaimed water being discharged and stored in the artificial lake. Since the reclaimed water was chlorinated before entering the lake, those pathogens detected were believed to result from microbial regrowth. The average concentration detected for $E$. coli in the Si-yuan artificial lake was $9.36 \times 10^{2}$ copies $/ 100 \mathrm{~mL}$, varying between $8.41 \times 10^{1}$ $3.50 \times 10^{3}$ copies $/ 100 \mathrm{~mL}$ with a standard deviation of $7.21 \times 10^{2}$; for Salmonella, the average concentration was detected to be $9.90 \times 10^{2}$ copies $/ 100 \mathrm{~mL}$ (range: $2.08 \times 10^{1}$ $9.45 \times 10^{3}$, standard deviation: $2.15 \times 10^{3}$ ), while for rotavirus, the average concentration was $1.60 \times 10^{1}$ copies $/ 100 \mathrm{~mL}$ (range: $1.32-2.32 \times 10^{2}$, standard deviation: $4.70 \times 10^{1}$ ). Exposure doses per day for these three pathogens from sprinkler irrigation, landscape fountains and toilet flushing were estimated, respectively, according to Eq. (1) and are summarized in Table 4. Results showed that, for different pathogens, the largest estimated exposure dose was for Salmonella at $1.90 \times 10^{3}$ copies/d, while for different exposure pathways, inhalation through sprinkler irrigation led to the maximum dose intake compared with other routes, which was estimated as $3.40 \times 10^{3}$ copies $/ \mathrm{d}$.

Table 4. Results of exposure doses per day, copies/d.

\begin{tabular}{lllll}
\hline Dose & E. coli & Salmonella & Rotavirus & Total \\
\hline Sprinkler irrigation & $1.64 \times 10^{3}$ & $1.73 \times 10^{3}$ & $2.85 \times 10^{1}$ & $3.40 \times 10^{3}$ \\
Landscape fountain & $1.58 \times 10^{2}$ & $1.67 \times 10^{2}$ & 2.74 & $3.27 \times 10^{2}$ \\
Toilet flushing & $9.36 \times 10^{-2}$ & $9.90 \times 10^{-2}$ & $1.63 \times 10^{-3}$ & $1.94 \times 10^{-1}$ \\
Total & $1.80 \times 10^{3}$ & $1.90 \times 10^{3}$ & $3.13 \times 10^{1}$ & \\
\hline
\end{tabular}

\subsection{Morbidity calculation}

Using Eq. (8) and Eq. (9), the probability of becoming ill per day $\left(P_{i l l / d}\right)$ and per year $\left(P_{i l l y}\right)$ were estimated and are summarized in Table 5. From this table, $P_{i l l / d}$ for $E$. coli was estimated 
to be $2.15 \times 10^{-16}$, which was much higher than for other pathogens. For Salmonella and rotavirus, $P_{\text {ill } / d}$ was estimated to be $1.52 \times 10^{-19}$ and $3.70 \times 10^{-17}$, respectively, which was low enough that the effect of illness for these two pathogens could be disregarded. For the different pathways, sprinkler irrigation led to the highest morbidity, while the probability of becoming ill from the other pathways was minimal; thus, these could be regarded as safer ways to reuse water. Results for $P_{\text {ill/y }}$ estimations were consistent with $P_{i l l / d} . P_{i l l y}$ caused by $E$. coli through sprinkler irrigation being the highest. Conversely, for other pathogens and through other pathways, $P_{i l l y}$ were very low and therefore disregarded.

Table 5. Results of morbidity.

\begin{tabular}{lllll}
\hline & E. coli & Salmonella & Rotavirus & Average \\
\hline $\mathrm{P}_{\text {ill/d }}$ & & & & \\
Sprinkler irrigation & $6.20 \times 10^{-16}$ & $4.52 \times 10^{-19}$ & $1.11 \times 10^{-16}$ & $2.44 \times 10^{-16}$ \\
Landscape fountains & $2.45 \times 10^{-17}$ & $4.40 \times 10^{-21}$ & $0^{\mathrm{a}}$ & $8.17 \times 10^{-18}$ \\
Toilet flushing & $0^{\mathrm{a}}$ & $0^{\mathrm{a}}$ & $0^{\mathrm{a}}$ & $0^{\mathrm{a}}$ \\
Average & $2.15 \times 10^{-16}$ & $1.52 \times 10^{-19}$ & $3.70 \times 10^{-17}$ & \\
& & & & \\
$\mathrm{P}_{\text {ill/y }}$ & & & $3.05 \times 10^{-14}$ & $7.12 \times 10^{-14}$ \\
Sprinkler irrigation & $1.83 \times 10^{-13}$ & $0^{\mathrm{a}}$ & $0^{\mathrm{a}}$ & $0^{\mathrm{a}}$ \\
Landscape fountains & $0^{\mathrm{a}}$ & $0^{\mathrm{a}}$ & $0^{\mathrm{a}}$ & $0^{\mathrm{a}}$ \\
Toilet flushing & $0^{\mathrm{a}}$ & $0^{\mathrm{a}}$ & $1.02 \times 10^{-14}$ & \\
Average & $6.11 \times 10^{-14}$ & $0^{\mathrm{a}}$ & $\mathrm{C}^{\mathrm{a}}$ & \\
\hline
\end{tabular}

a The calculated value is less than $10^{-30}$, therefore, in the excel spreadsheet, it is determined as 0 by default.

\subsection{DALY calculation}

Disease burdens were calculated using Eq. (10) to Eq. (12) and results are shown inTable 6. From this table, the burdens of disease for E. coli, Salmonella and rotavirus were calculated as $2.46 \times 10^{-13}, 0$ and $8.50 \times 10^{-14}$ DALYs per person per year (pppy), respectively, among which disease burden due to $E$. coli made the largest contribution to the total burden of disease estimates, while disease burdens caused by Salmonella androtavirus were very low and therefore disregarded. As a result, E. coli was identified as the major risk factor leading to potential health hazard regarding to water reuse in Xi'an Si-yuan University. Compared with different pathways, disease burden due to sprinkler irrigation accounted for almost $100 \%$ of the total burden of disease estimates, while through other pathways, the disease burdens were very low thus disregarded. Therefore, sprinkler irrigation was regarded as the major source to spread microbiological contamination regarding water reuse in Xi'an Si-yuan University. 
According to the above results, disease burden calculated by the DALY can provide useful information for risk assessment associated with the process of wastewater reuse. Disease burden obtained by DALY can also assist in decision-making regarding environmental pollution control and prevention. As a new indicator implemented to quantify health impact due to environmental pollution, disease burden interpreted in terms of DALY is a modification of traditional risk assessment method by extending its endpoint from infection rate to possible health impact. With reference to disease probabilities and disease characters under various health conditions, the DALY was successfully applied in this study to interpret the extent of health damage after wastewater reclamation and utilization.

Table 6. Results of disease burden calculation, DALYs.

\begin{tabular}{llllll}
\hline DALY & E. coli & Salmonella & Rotavirus & Total & Percentage \\
\hline Sprinkler irrigation & $2.46 \times 10^{-13}$ & $0^{\mathrm{a}}$ & $8.50 \times 10^{-14}$ & $3.31 \times 10^{-13}$ & $100.00 \%$ \\
Landscape fountains & $0^{\mathrm{a}}$ & $0^{\mathrm{a}}$ & $0^{\mathrm{a}}$ & $0^{\mathrm{a}}$ & $0.00 \%{ }^{\mathrm{a}}$ \\
Toilet flushing & $0^{\mathrm{a}}$ & $0^{\mathrm{a}}$ & $0^{\mathrm{a}}$ & $0^{\mathrm{a}}$ & $0.00 \%{ }^{\mathrm{a}}$ \\
Total & $2.46 \times 10^{-13}$ & $0^{\mathrm{a}}$ & $8.50 \times 10^{-14}$ & $3.31 \times 10^{-13}$ & \\
Percentage & $74.35 \%$ & $0.00 \%^{\mathrm{a}}$ & $25.65 \%$ & & \\
\hline
\end{tabular}

a The calculated value is less than $10^{-30}$, therefore, in the excel spreadsheet, it is determined as 0 by default.

\section{Conclusions}

This study was conducted to quantitatively assess the health impacts of water reuse in Xi'an Si-yuan University. Combining epidemiological investigation of waterborne diseases and field surveys of local exposure characteristics, typical pathogens were selected and major exposure routes were identified. Health impacts attributed to the selected pathogens were evaluated in terms of disease burden by using DALY. According to the results and discussion above, the following conclusions can be drawn:

(1) Disease burden evaluated by DALY can provide a comprehensive method of interpreting the health hazards caused by microbiological contaminants. As a supplement to and extension of traditional health risk assessment, health hazards evaluated by DALY can not only complete and verify the result of infection risk assessment, but also provide a better understanding of the ultimate health impact due to environmental pollution.

(2) By introducing immune status and age effect, a modification of original doseresponse equation was implemented, and the construction of dose-morbidity 
relationship was accomplished via a Gamma distribution to account for the duration of infection. On this basis, the establishment of a methodology from exposure dose calculation to disease burden evaluation was eventually developed.

(3) The established model and methodology has been successfully applied to the analysis of health impact due to water reuse in Xi'an Si-yuan University. Calculation results showed that $E$. coli was the major microbiological contaminant while sprinkler irrigation emerged as the most significant exposure route for creating the greatest burden of disease from water reuse in Xi'an Si-yuan University.

\section{Acknowledgements}

This work was supported by the National Natural Science Foundation of China (No.51308439), JSPS Special Program (15F15353), the Shaanxi Provincial Natural

Science Foundation (Grant No. 2015JM5161), and the Program for Innovative Research Team in Shaanxi Province (Grant No. 2013KCT-13).

\section{References}

Ahmed, W., Tucker, J., Bettelheim, K.A., 2007. Detection of virulence genes in Escherichia coli of an existing metabolic fingerprint database to predict the sources of pathogenic E. coli in surface waters. Water Res. 41 (16), 3785-3791.

Asano, T., 1998.Wastewater Reclamation and Reuse. Technomic Publishing Co, Singapore.

Beyer, KirstenM.M., 2016. Chapter 10 - chronic environmental diseases: burdens, causes, and response. Biological and Environmental Hazards, Risks, and Disasters 5, 191-217.

Bitton, G., 2005.Wastewater Microbiology. third ed. JohnWiley \& Sons, Inc., Hoboken, NJ.

Bixio, D., Thoeye, C., De Koning, J., Joksimovic, D., Savic, D., Wintgens, T., Meli, T., 2006. Wastewater reuse in Europe. Desalination 187, 89-101.

Brissaud, F., 2001. Role ofwater reuse enhancing integratedwater management in Europe and Mediterranean countries. Water Sci. Technol. 43 (10), 25-33.

Chen, H., Chen, H., He, J., Liu, F., Shen, Z., Han, B., et al., 2006. Health-based risk assessment of contaminated sites: principles and method. Earth Sci. Front. 13, 216-223.

Cui, H., 2005. Legal report of infectious diseases for Xi'an. J. Pract. Med. Tech. 12, 11841191.

Dan, Li, Zeng, Siyu, Gu, April Z., He, Miao, Shi, Hanchang, 2013. Inactivation, reactivation and regrowth of indigenous bacteria in reclaimed water after chlorine disinfection of a municipal wastewater treatment plant. J. Environ. Sci. 25 (7), 1319-1325.

Dorevitch, Samuel, Panthi, Suraj, Huang, Yue, Li, Hong, Michalek, Angela M., Pratap, Preethi, Wroblewski, Meredith, Liu, Li, Scheff, Peter A., Li, An, 2011. Water ingestion during water recreation. Journal of Water Res. 45, 2020-2028. 
Gao, T., Wang, X., Chen, R., Ngo, H., Guo, W., 2015. Disability adjusted life year (DALY): a useful tool for quantitative assessment of environmental pollution. Sci. Total Environ. 511, $268-287$.

Geelen, L.M.J., Huijbregts, M.A.J., Den Hollander, H., Ragas, A.M.J., Van Jaarsveld, H.A., De Zwart, D., 2009. Confronting environmental pressure, environmental quality and human health impact indicators of priority air emissions. Atmos. Environ. 43, 1613-1621.

Gerba, C.P., Singh, S.N., Rose, J.B., 1985.Waterborne gastroenteritis and viral hepatitis. CRC Crit. Rev. Environ. Cont. 15, 213-236.

Gu, S., Song, G., Zhou, F., Ji, W., Yang, Q., 2002. The application of DALY for health state evaluation of the resident of Shanghai. Journal of Preventive Medicine of Shanghai. 55, 143155.

Haas, C.N., Rose, J.B., Gerba, C.P., 1999. Quantitative Microbial Risk Assessment. JohnWiley \& Sons, NewYork.

Hamilton, A.J., Stagnitti, F., Xiong, X., Kreidl, S.L., Benke, K.K., Maher, P., 2007.Wastewater irrigation: the state of play. Vadose Zone J. 6, 823-840.

Havelaar, A.H.,Melse, J.M., 2003. Quantifying public health risk in the WHO guidelines for drinking water quality: a burden of disease approach. Water Health 6, 57-65.

He, X., Ma, S., Li, A., Pan, X., Chen, Q., Wang, J., 2006. Exposure assessment of various reclaimed water uses. Environ. Sci. 27, 1912-1915.

Lazarova, V., Levine, B., Sack, J., Cirelli, G., Jeffrey, P., Muntau, H., Salgot, M., Brissaud, F., 2001. Role of water reuse enhancing integrated water management in Europe and Mediterranean countries. Water Sci. Technol. 43 (10), 25-33.

Lin, Y., Li, D., Gu, Zeng S., He, M., 2016. Bacterial regrowth in water reclamation and distribution systems revealed by viable bacterial detection assays. Chemosphere 144, 21652174.

Murray, C.J.L., Lopez, A.D., 1996. The Global Burden of Disease. World Health Organization, Geneva.

Murray, C.J., Lopez, A.D., 1997. Globalmortality, disability, and the contribution of risk factors: global burden of disease study. Lancet 349, 1436-1442.

Oliver, James D., 2005. The viable but nonculturable state in bacteria. J. Microbiol. 7, 93100 .

Pang, X.L., Lee, B., Boroumand, N., 2004. Increased detection of rotavirus using a real time reverse transcription-polymerase chain reaction (RT-PCR) assay in stool specimens from children with diarrhea. J. Med. Virol. 72, 496-501.

Rahn, K., Grandis, S.A.D., Clarke, R.C., 1992. Amplification of an invA gene sequence of Salmonella typhimurium by polymerase chain reaction as a specific method of detection of Salmonella. Mol. Cell. Probes 6 (4), 271-279.

Tao, Q., He, P., Xie, Y., 2003. Analysis of prevalence reasons for typhoid and paratyphoid. Journal of China Public Health 19, 1149-1150. 
Teunis, P.F.M., van der Heijden, O.G., van der Giessen, J.W.B., Havelaar, A.H., 1996. The Dose-Response Relation in Human Volunteers for Gastro-Intestinal Pathogens. National Institute of Public Health and the Environment (RIVM), The Netherlands.

Teunis, F.M., Nagelkerke, N.J.D., Haas, C.N., 1999. Dose response models for infectious gastroenteritis. Risk Anal. 19, 1251-1260.

Teunis, F.M., Chappell, C.L., Okhuysen, P.C., 2002. Cryptosporidiumdose-response studies: variation between hosts. Risk Anal. 22, 475-485.

USEPA, 1997. Exposure Factors Hand Book Washington, DC. EPA/600/P-95/002Fa .

Van Nevel, Sam, De Roy, Karen, Boon, Nico, 2013. Bacterial invasion potential in water is determined by nutrient availability and the indigenous community. Journal of Microbiology Ecology 85, 593-603.

Verlicchi, P., Galletti, A., Aukidy, M.A., Masotti, L., 2011. New perspectives in wastewater disinfection. In: Buchanan, Kelly M. (Ed.), Water Disinfection. Nova Publisher, pp. 77-108.

Wei, A., Zhang, D., Xiao, S., Yu, J., Yang, M., 2012. Risk assessment of giardia in rivers of Southern China based on continuous monitoring. J. Environ. Sci. 24, 309-313.

WHO, 2013. WHO Methods and Data Sources for Global Burden of Disease Estimates 2000-2011. Department of Health Statistics and Information Systems WHO, Geneva.

Xie, X., Hu, H., Guo, M., Wu, Q., 2009. Assessment method of the pathogenic microbial exposure caused by aerosolization of reclaimed water. Environ. Sci. 30, 70-74. 